OPEN ACCESS

Edited by:

Marianne Boes,

Utrecht University, Netherlands

Reviewed by:

Stephen Nutt,

Walter and Eliza Hall Institute of

Medical Research, Australia

Francisco Borrego,

BioCruces Health Research

Institute, Spain

*Correspondence:

Ali A. Ashkar

ashkara@mcmaster.ca

Specialty section:

This article was submitted to

NK and Innate Lymphoid Cell Biology,

a section of the journal

Frontiers in Immunology

Received: 15 April 2019

Accepted: 04 June 2019

Published: 19 June 2019

Citation:

Poznanski SM and Ashkar AA (2019) What Defines NK Cell Functional Fate:

Phenotype or Metabolism?

Front. Immunol. 10:1414.

do: $10.3389 /$ fimmu.2019.01414

\title{
What Defines NK Cell Functional Fate: Phenotype or Metabolism?
}

\section{Sophie M. Poznanski and Ali A. Ashkar*}

Department of Pathology and Molecular Medicine, McMaster Immunology Research Centre, McMaster University, Hamilton, ON, Canada

NK cells are capable of an array of functions that range widely from their classic anti-tumor and anti-viral cytotoxic effector functions, to their critical regulatory roles in controlling inflammatory immune responses and promoting tissue growth. However, the mechanisms that polarize NK cells to these distinct and opposing functions are incompletely understood. NK cell functional subsets are primarily identified and studied based on phenotype, which has served as an accessible means for profiling NK cells and does offer information on NK cell activation state. However, inconsistencies have emerged in using classic phenotypes to inform function, which raise the questions: Can phenotype in fact define NK cell functional fate? What factors do profile and drive NK cell fate? In other immune cells, cell metabolism has been shown to critically determine subset polarization. There is a growing body of evidence that cell metabolism is integral to NK cell effector functions. Glucose-driven glycolysis and oxidative metabolism have been shown to drive classic NK cell anti-tumor and anti-viral effector functions. Recent studies have uncovered a critical role for metabolism in NK cell development, education, and memory generation. In this review, we will draw on the evidence to date to investigate the relationship between NK cell phenotype, metabolism, and functional fate. We explore a paradigm in which the differential activity of metabolic pathways within NK cells produce distinct metabolic fingerprints that comprehensively distinguish and drive the range of NK cell functional abilities. We will discuss future areas of study that are needed to develop and test this paradigm and suggest strategies to efficiently profile NK cells based on metabolism. Given the emerging role of metabolism in driving NK cell fates, profiling and modulating NK cell metabolism holds profound therapeutic potential to tune inflammatory and regulatory NK cell responses to treat disease.

Keywords: NK cell, cell metabolism, phenotype, NK cell subsets, glycolysis, mitochondria, CD56, innate immunity

\section{INTRODUCTION}

Natural Killer (NK) immune cells are capable of an array of functions that range widely from their classic innate anti-tumor and anti-viral effector functions, to their regulatory roles in modulating other immune cells and promoting tissue growth (1). These distinct functions play critical yet paradoxical roles in a host of diseases. Cytotoxic NK cells are known to have an imperative role in the clearance of virally-infected and malignant cells (2); however, signals in the tumor environment polarize NK cells to regulatory subsets that support tumor progression and suppress other cytotoxic immune cells (3-5). While pathogenic in the context of cancer, regulatory NK cells have critical homeostatic roles in tissue growth and immune tolerance in contexts such as placental development 
and fetal tolerance in pregnancy (6-8), and regulating fibrosis and immune cells in the liver (9-11). Despite the critical importance of mounting the appropriate NK cell response in different disease contexts, the mechanisms that polarize NK cells to these distinct and opposing functional fates are incompletely understood.

To date, NK cell functional subsets have been primarily identified and studied based on phenotypic markers. In their most classic definition, human NK cells are broadly dichotomized into $\mathrm{CD} 56^{\text {bright }} \mathrm{CD} 16^{-}$regulatory $\mathrm{NK}$ cells with greater cytokine-producing capabilities, and $\mathrm{CD} 56^{\mathrm{dim}} \mathrm{CD} 16^{+}$ anti-tumor/anti-viral NK cells with greater cytotoxic functions $(12,13)$. Additional receptor families function to tune NK cell activation and effector responses; these include activating Natural Cytotoxicity Receptors (NKp30, NKp44, and NKp46), activating and inhibitory CD94/NKG2 receptors that recognize non-classical MHC, and inhibitory KIR receptors that recognize classical MHC. The differential expression of these receptors is used to further specify NK cell developmental stages, effector subsets, and memory populations (14). Although phenotype is an accessible means by which to profile NK cells and provides information on NK cell activation state, reports are increasingly emerging that highlight discrepancies between NK cell phenotypic classification and their effector functions. These discrepancies present the questions: Can phenotype in fact define NK cell functional fate? What factors do define and drive NK cell fate?

A cell's ability to generate energy through metabolism enables its functional capacities. Indeed, there is a growing body of evidence that cell metabolism is integral to NK cell effector functions. It has been established that glucose-driven glycolysis and oxidative metabolism are required for classic NK cell antitumor and anti-viral effector functions (15-18). Recent studies have also emerged that point to critical roles of metabolism in NK cell development, education, and memory responses (19-23). In other immune cell subsets including $\mathrm{T}$ cells and macrophages, cell metabolism critically determines subset polarization. Upregulation of glycolytic metabolism drives the polarization of pro-inflammatory $\mathrm{T}$ cells and macrophages (24-27). In contrast, a shift to respiration-derived ATP drives the polarization and functions of regulatory macrophages and T cells $(24-26,28)$. The generation of memory in $\mathrm{T}$ cells is marked by an increase in mitochondrial respiratory capacity, which enables a more rapid and robust secondary immune response (29, 30). Even within a terminally polarized subset, the activation of different metabolic pathways leads to distinct functional outcomes (31). While metabolism has been shown to regulate certain NK cell effector functions, the role of metabolism in broadly determining and defining different $\mathrm{NK}$ cell functional fates remains to be fully characterized.

Herein, we explore the relationship between NK cell phenotype, metabolism, and functional fate. Drawing on the evidence to date, we investigate the utility and roles of NK cell phenotype and metabolic activity in identifying and determining NK cell effector fate. We propose that differential activity in NK cell metabolic pathways, but not phenotype, produces distinct and subset-defining fingerprints that comprehensively distinguish and drive the range of possible NK cell functional abilities.

\section{NK CELL FATE BASED ON PHENOTYPE: CAN WE JUDGE A BOOK BY ITS COVER?}

For decades, NK cell phenotype has been integrally conflated with effector function and used as the principle means of classifying NK cells into distinct subsets. For instance, the stages of NK cell maturation are demarcated by the expression of specific phenotypic markers. Less mature human peripheral blood (pb)NK cells are defined as $\mathrm{CD} 56^{\text {bright }} \mathrm{CD} 16^{-}$and express CD94 and the NKG2A inhibitory receptor $(32,33)$. As NK cells mature, they down-regulate CD56 expression and up-regulate CD16, becoming CD56 ${ }^{\mathrm{dim}} \mathrm{CD} 16^{+}$(34). These lose expression of NKG2A and acquire expression of KIR inhibitory receptors. A final step of NK cell maturation is marked by the acquisition of CD57. CD56 ${ }^{\text {dim }} \mathrm{CD} 57^{+} \mathrm{NK}$ cells are considered to be the most mature and terminally differentiated subset (32).

Contrary to this classic maturation paradigm, it is now understood that CD56 ${ }^{\text {dim }} \mathrm{NK}$ cells can in fact up-regulate CD56 expression upon cytokine activation and become CD56 ${ }^{\text {bright }}$ (35). Thus, high CD56 expression does not necessarily differentiate less mature from mature NK cells, as it can also indicate mature, activated NK cells. Other recent studies provided evidence that $\mathrm{CD}_{57}{ }^{+} \mathrm{NK}$ cells are not terminally differentiated. It was found that upon single cell expansion with K562 feeder cells, some clones derived from originally $\mathrm{CD} 56^{\mathrm{dim}} \mathrm{CD} 57^{+} \mathrm{NK}$ cells had lost CD57 expression. Moreover, clones from NKG2A populations were capable of reacquiring NKG2A expression (36). Following autologous stem cell transplant in patients with lymphoma or myeloma, a unique CD56 bright $\mathrm{NK}$ cell population was found to be the predominant NK cell subset following leukocyte regeneration. These young CD56 bright $\mathrm{NK}$ cells had high expression of CD57 and KIRs and potent degranulation (37). These studies demonstrate that unless NK cells are capable of regressing through maturation, classic NK cell development markers cannot definitively specify the stage of NK cell maturation.

Recent studies have also introduced discrepancies in the CD56 ${ }^{\text {bright }} / \mathrm{CD} 56^{\text {dim }}$ phenotypic dichotomization of regulatory and cytotoxic NK cells. Wagner et al. demonstrated that following priming with IL-15, CD56 ${ }^{\text {bright }}$ pbNK cells not only had greater cytokine production compared to CD $56^{\mathrm{dim}}$ pbNK cells, but also displayed greater degranulation and killing in response to tumor cell targets. Importantly, they negated the possibility that this was due to up-regulation of CD56 on CD56 ${ }^{\mathrm{dim}} \mathrm{NK}$ cells, as they observed this effect even with pre-sorted CD56 ${ }^{\text {bright }} \mathrm{NK}$ cells (38). In addition, evidence has emerged to suggest that CD56 ${ }^{\text {bright }}$ does not unanimously define NK cells with the strongest cytokine-producing capabilities. The hepatic NK cell population is highly enriched in CD56 $6^{\text {bright }}$ cells compared to pbNK cells; yet, these have recently been shown to have reduced IFN- $\gamma$ and $\mathrm{TNF} \alpha$ production in response to stimulation compared to pbNK cells, despite the majority of pbNK cells being CD56 $6^{\mathrm{dim}}$ (39). Building further on this phenomenon, CD56 $6^{\text {superbright }}$ 
NK cells are considered highly immunoregulatory. Notably, CD56 ${ }^{\text {superbright }} \mathrm{CD} 16^{-}$uterine $\mathrm{NK}$ cells are instrumental in promoting angiogenesis and tissue remodeling required for healthy placental development in pregnancy. These regulatory functions lend themselves as well to enhancing, rather than inhibiting, tumor progression (7). However, in stark contrast to their characteristic regulatory functions, highly cytotoxic CD56 $6^{\text {superbright }} \mathrm{NK}$ cells produced following NK cell expansion with K562-based feeder cells were recently described. These CD56 $6^{\text {superbright }}$ expanded NK cells eliminated large ovarian tumors in xenograft models. What's more, within the expanded NK cell population, degranulation, cytotoxicity, and IFN- $\gamma$, increased with increasing CD56 brightness (40). Together, these studies indicate that CD56 expression cannot distinguish regulatory from cytotoxic NK cells. Indeed, CD56 ${ }^{\text {bright }} \mathrm{NK}$ cells can be any combination of mature or less mature, and cytotoxic or regulatory.

Since CD $56^{\text {bright }}$ NK cells can be either cytotoxic or regulatory, the question that pursuantly arises is whether another phenotypic marker may better define these functional subsets. CD16 expression is classically used in conjunction with CD56, with $\mathrm{CD} 16^{+} \mathrm{NK}$ cells considered cytotoxic and $\mathrm{CD}^{-} 6^{-} \mathrm{NK}$ cells categorized as regulatory (13). It has been demonstrated that upon activation, $\mathrm{CD} 56^{\mathrm{dim}} \mathrm{CD} 16^{+} \mathrm{NK}$ cells up-regulate $\mathrm{CD} 56$, culminating in a $\mathrm{CD} 56^{\text {bright }} \mathrm{CD} 16^{+}$cytotoxic $\mathrm{NK}$ cell population (35). Thus, it could be postulated that CD16 expression distinguishes $\mathrm{CD} 56^{\text {bright }}$ cytotoxic and regulatory NK cells. However, highly cytotoxic IL-15-primed CD56 ${ }^{\text {bright }}$ NK cells remained predominantly $\mathrm{CD}^{-} 6^{-}$(38). Moreover, Siewiera et al. have demonstrated regulatory capacities in $\mathrm{CD}^{+} 6^{+} \mathrm{NK}$ cells. They reported that following culture in TGF- $\beta$ /IL15/IL18, pbNK cells acquired regulatory functions, as they produced high levels of VEGF, and had reduced cytotoxicity and production of IFN$\gamma$ and TNF $\alpha$, but retained high expression of CD16 (41). These studies call into question the relevance of CD16 for determining cytotoxic and regulatory NK cell subsets.

Turning to other NK cell markers does not seem to address the above discrepancies. Both regulatory and cytotoxic NK cells can express high levels of activating receptors including NKG2D, NKp30, NKp44, and NKp46, but stimulation through these receptors instigates distinct functions in regulatory and cytotoxic NK cells $(7,41,42)$. While it has been reported that expression of different splice variants in these receptors partly contributes to determining downstream function (41), the fundamental mechanisms that determine the receptor isoform expressed remain unknown. Inhibitory receptor expression is equally uninformative, as both regulatory and cytotoxic NK cells can express high or low levels of NKG2A and/or KIRs (32, 38, $40,43,44)$. In all, a specific combination of NK cell phenotypic markers that consistently distinguishes regulatory from cytotoxic NK cells remains elusive (Figure 1).

A similar challenge arises in phenotypically defining memory NK cells. Memory NK cells are generated in response to a number of stimuli, including hapten-induced contact hypersensitivity, infections, cytokine activation, and pregnancy (6, 45-47). Secondary responses of memory NK cells are variegated and depend on the sensitizing stimulus. Some memory NK cells have adaptive-like antigen-specific secondary responses, while others have an innate-like non-antigen-specific recall response $(46,47)$. What's more, memory responses have now been identified in both cytotoxic and regulatory NK cells $(6,45)$. However, what does remain consistent and broadly defines memory subsets is their functional capacity to have a rapid and enhanced response upon re-stimulation.

Studies have largely used phenotypic markers to define memory NK cells. Extensively studied memory NK cells include those generated in response to cytomegalovirus (CMV) infection. In humans, these have been predominantly defined as $\mathrm{CD}_{56}{ }^{\mathrm{dim}} \mathrm{NKG} 2 \mathrm{C}^{+} \mathrm{NK}$ cells, which preferentially expand in response to acute infection. These $\mathrm{NKG}_{2} \mathrm{C}^{+} \mathrm{NK}$ cells undergo contraction following acute infection, but persist long-term and specifically increase in response to human CMV (HCMV) reactivation and produce high levels of IFN- $\gamma$ (48). Certainly, NKG2C plays a direct role in shaping HCMV adaptive NK cell responses. NKG2C on HCMV-adaptive NK cells has been shown to display fine peptide specificity through differential recognition of polymorphic UL40-encoded peptides. These UL40 polymorphisms enabled selective recognition of distinct strains of HCMV and selective activation, proliferation, and differentiation of $\mathrm{NKG}_{2} \mathrm{C}^{+}$adaptive $\mathrm{NK}$ cells (49). HCMV memory NK cells are considered to have a mature phenotype, as they lack NKG2A, have lower levels of NKp30 and NKp46, and have high KIR and CD57 expression (22, 48, 50). Although NKG2C is principally used to identify HCMV-memory NK cells, recent studies have challenged the requirement for NKG2C in generating HCMV-memory NK cells. Memory NK cell responses to HCMV have been reported in NKG2C-deficient humans and upon HCMV re-activation in patients transplanted with NKG2C-deficient cord blood $(51,52)$. Therefore, expression of NKG2C is not necessary to define HCMV-memory NK cells.

In addition, memory NK cells do not unanimously express a classically mature phenotype. Cytokine-induced memorylike (CIML) NK cells generated by IL-12/IL-15/IL-18 preactivation are primarily CD56 ${ }^{\mathrm{dim}}$, but express CD25, NKG2A, CD94, and CD69, and lack expression of KIRs and CD57 $(53,54)$. Memory NK cells are also not limited to the CD56 ${ }^{\text {dim }}$ compartment. Frequencies of long-lived BCG-reactive CD56 ${ }^{\text {bright }}$ and CD56 ${ }^{\text {dim }} \mathrm{NK}$ cells were shown to be elevated for up to 1 year after BCG re-vaccination in adults and were predominantly KIR2DL2/DL3 ${ }^{-}$and $\mathrm{CD}^{-} 7^{-}$. BCG revaccination induced greater IFN- $\gamma$ expression in both CD56 $6^{\text {bright }}$ and CD56 ${ }^{\mathrm{dim}} \mathrm{NK}$ cells for up to 1 year compared to NK cells prior to BCG re-vaccination. Furthermore, perforin expression was also enhanced upon BCG stimulation in CD56 ${ }^{\text {bright }}$ NK cells 1 year following BCG-revaccination, compared to CD56 ${ }^{\text {bright }} \mathrm{NK}$ cells pre-BCG-revaccination (55). Recently, memory NK cells have been described in the context of pregnancy. Pregnancytrained memory uterine NK cells (PTuNKs) were reported in the deciduae of multigravid women. PTuNK cells have enhanced regulatory function including VEGF production, relative to uNK cells from primigravid deciduae, which supported enhanced vascularization and tissue growth. Given their tissueresidency, it is perhaps not surprising that PTuNK cells have a unique phenotype relative to other memory subsets, as they 


\section{Cytotoxic}

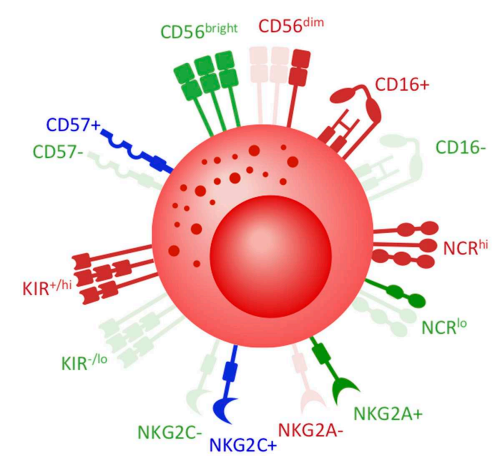

Regulatory

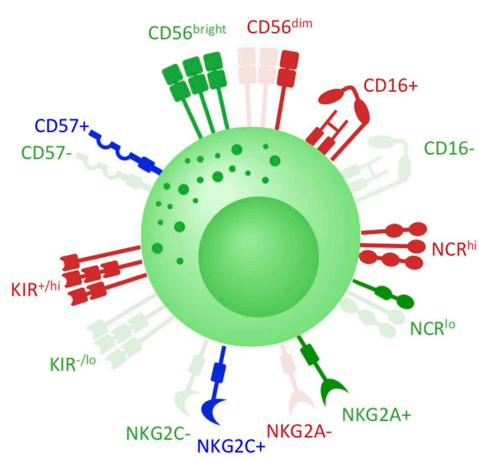

Memory

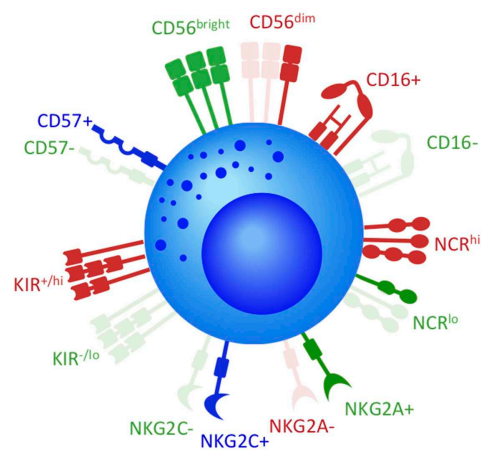

FIGURE 1 | Same covers, different stories: phenotype does not distinguish NK cell functional fates. To date, phenotype has been used as a principal means of studying and classifying NK cell functional subsets. However, there is mounting evidence that demonstrates significant discrepancies in the classic phenotype definition of NK cell subsets. For instance, while cytotoxic NK cells are classically defined as CD56 ${ }^{\text {dim }}$ CD16 ${ }^{+}$, recent studies have demonstrated that CD56 ${ }^{\text {bright }}$ NK cells in fact hold the greatest cytotoxic potential. It has now been shown that regulatory NK cells, classically defined as CD56 ${ }^{\text {bright }}$ CD16 ${ }^{-}$, can also in fact express CD16. Memory NK cells also present as either CD56 bright or CD56 ${ }^{\text {dim }}$ and CD16 ${ }^{+}$or CD16 ${ }^{-}$. Other phenotypic markers do not further distinguish NK cell subsets: cytotoxic, regulatory, and memory NK cells can all express either high, low, or absent levels of Natural Cytotoxicity Receptors (NCRs), NKG2A, NKG2C, KIRs, and CD57. Thus, not only can NK cells with the same functional fate express a range of possible phenotypes, but NK cells with opposing functions can express the same phenotype. Indeed, the range of classic NK cell phenotypic profiles are expressed across NK cell fates and are thus insufficient to distinguish NK cell functional subsets. Red denotes receptors classically associated with cytotoxic NK cells; green denotes receptors classically associated with regulatory NK cells; blue denotes receptors classically associated with memory NK cells.

were predominantly $\mathrm{CD} 56^{\text {bright }} \mathrm{CD} 16^{-}$, expressed high levels of NKG2C, but unchanged levels of NKp30 and NKp46 (6). It is possible that certain phenotypic traits may distinguish antigenspecific from non-specific memory NK cells. Nevertheless, there remains no unifying phenotype to identify NK cells with memory capacity (Figure 1). Furthermore, the mechanisms within NK cells that ultimately drive and identify the capacity for an enhanced secondary response are not fully elucidated.

If phenotype is unable to consistently identify NK cell subsets and functional fate (Figures 1, 2A), what other factors might achievably distinguish NK cell fate? Such identifying features likely lie at the heart of mechanisms that drive NK cell function.

\section{IF AN NK CELL CANNOT BE DEFINED BY HOW IT LOOKS, COULD IT BE DEFINED BY HOW IT IS FUELED?}

As highly plastic innate responders, NK cell effector fate is molded by its environment. NK cells integrate a number of environmental cues which determine downstream function. In the absence of activating signals, naïve NK cells remain in a resting quiescent state. In response to inflammatory signals, cytotoxic effector NK cell responses are marked by robust proliferation and synthesis of proinflammatory cytokines and cytotoxic machinery. Upon resolution of inflammation, NK cells curb their response, returning to a quiescent state. It is noteworthy that this shifting functional profile represents a profound shift in energy dynamics from a low-energy quiescent state to one with substantial energetic and biosynthetic requirements. Further, NK cells exert distinct functions across different tissue sites that vary greatly in nutrient types and availability. From these factors arises a parallel between NK cell energetics and functional fates.

Indeed, the capacity of a cell to generate energy through metabolism has emerged as an important factor in enabling immune cell effector functions. The burgeoning field of NK cell metabolism has uncovered the involvement of cell metabolism throughout different steps of NK cell fate determination, including development, cytotoxic effector responses, and generation of long-lived memory populations. Thus, could distinct metabolic profiles comprehensively identify and drive NK cell functional fates?

\section{At Their Inception, NK Cell Development Is Enabled by Metabolic Signals}

NK cell development is an energy-intensive process as it requires high levels of proliferation of NK cells in the bone marrow. As NK cells progress through development, their proliferation slows and they progress to state of quiescence in the periphery $(56,57)$. In line with this, gene expression analysis has demonstrated that metabolic pathways associated with cell growth are up-regulated in developing NK cells whereas gene signatures associated with metabolic quiescence, such as fatty acid catabolism and aerobic metabolism, are predominant in resting NK cells in the periphery (56). While studies have yet to comprehensively measure the metabolic activity of NK cells at different stages of development, key metabolic regulators have emerged as pivotal drivers of NK cell maturation.

The mechanistic target of rapamycin (mTOR) is a major energy sensor in the cell that integrates signals for nutrient availability, growth, and activation. In response to such signals, 
mTOR up-regulates glycolytic metabolism and biosynthetic processes (58). A seminal study by Marçais et al. revealed the critical role for mTOR in murine NK cell development. They found that mice with an NK cell-specific deletion of mTOR had normal levels of developing NK cells in the bone marrow, but only trace levels of NK cells in the periphery (56). Other studies have further demonstrated that mTOR signaling is required for the early stages of NK cell development $(19,20)$. The protein E4BP4 plays an indispensible role in the commitment to the NK cell lineage by promoting the transcription of Eomes (59). Downstream of IL-15 signaling, mTOR activation by the kinase PDK1 was found to be required for E4BP4 expression in bone marrow NK cells. Indeed, knock-out of PDK1 in NK cells arrested NK cell development in early stages by inhibiting mTOR activation and reducing expression of the transferrin receptor CD71 and the amino acid transporter CD98 (20). Tight regulation of mTOR activity is critical for NK cell development, as the expression of $T s c 1$, a repressor of $\mathrm{mTOR}$, is required to prevent deregulated proliferation and resulting exhaustion in response to IL-15 in developing NK cells (19). Together, these studies present mTOR-mediated metabolic signaling as a central node in NK cell development.

The evidence to date has demonstrated the requirement for metabolic regulators in $\mathrm{NK}$ cell development and that a shifting metabolic expression profile parallels development. These studies portray a baseline energy-intensive, biosynthetic metabolic fingerprint for developing NK cells in the bone marrow, which shifts to a more energy-conservative fingerprint as NK cells progress to the periphery. Further developing and characterizing the metabolic fingerprints of NK cells throughout development may more broadly define the maturation stages of NK cells, particularly for later stages in which phenotype fails to do so and for NK cells at different tissue sites. Assessing the baseline metabolic fingerprint in such instances holds potential to more comprehensively define the degree of NK cell maturity.

\section{Greater Glucose-Driven Metabolic Fitness Identifies NK Cells With the Greatest Cytotoxic Capacity}

Although metabolically quiescent at baseline, mature cytotoxic NK cells up-regulate the rate of glucose-driven glycolysis and oxidative phosphorylation (OxPhos) upon stimulation (15-17, $60,61)$. Increases in these metabolic pathways are accompanied by increased expression of the nutrient receptors Glut1, CD71, and CD98 $(16,56,60)$. Activated cytotoxic NK cells primarily rely on glucose to fuel mitochondrial ATP production, as inhibition of glycolysis via the competitive inhibitor 2-deoxyglucose (2DG) impaired ATP production comparably to direct inhibition of OxPhos by the ATP synthase inhibitor oligomycin (61). The activation-induced increase in NK cell glucose metabolism has been shown to be regulated by mTOR, glutamine, and transcription factors cMyc and Srebp. mTOR activity is highly up-regulated in $\mathrm{NK}$ cells in response to stimulation $(16,56$, 60,62 ). In murine NK cells, knock-out or inhibition of mTOR has been shown to prevent the increases in glycolysis, glycolytic enzymes, and nutrient receptor expression upon activation (16,
56, 63). Similarly in human NK cells, the up-regulation of glycolysis in response to IL-15 and IL-2 is dependent upon mTOR, although independent from mTOR in response to IL15/IL-12 stimulation (60). cMyc is another key driver of glucose metabolism in immune cells (64). In response to IL-2/IL-12 stimulation, glutamine uptake by NK cells was found to drive the expression of $\mathrm{cMyc}$ which in turn was required for the activationinduced increase in glycolysis and OxPhos by up-regulating glycolytic machinery and mitochondrial biogenesis (17). Srebp transcription factors promote the catabolism of glucose to cytosolic citrate in NK cells by supporting the activity of the citrate-malate shuttle which shuttles glucose-derived citrate from the mitochondria to the cytosol. Activity of the shuttle in turn produces mitochondrial NADH which fuels elevated OxPhos in NK cells (15).

This up-regulation in glucose-driven glycolysis and OxPhos is critical for NK cell cytotoxicity and IFN- $\gamma$ production. Direct inhibition of glycolysis in murine NK cells, by 2DG or by substituting glucose with galactose in culture, inhibited IFN$\gamma$ and granzyme B expression in response various modes of stimulation including TLR-, cytokine-, or activation receptormediated stimulation $(16,61)$. In line with the evidence that glucose is the primary fuel driving OxPhos in cytotoxic NK cells, inhibition of OxPhos by glucose-depleted media or the ATP synthase inhibitor oligomycin also potently inhibited receptormediated IFN- $\gamma$ production (61). Mah et al. demonstrated the pivotal role for $\mathrm{NK}$ cell glucose metabolism in the defense against infection: inhibition of glycolysis with 2DG impaired NK cell clearance of MCMV-infected cells in mice and compromised control of viremia and resulting survival of the mice (18). Arrest of NK cell glucose metabolism has also been shown to play a critical role in obesity-induced NK cell dysfunction. The increased presence of fatty acids in obesity led to lipid accumulation in NK cells, resulting in a PPAR-mediated increase in NK cell lipid metabolism and abrogation of glycolysis and OxPhos. These metabolic changes impaired polarization of cytotoxic machinery and resulting anti-tumor NK cell functions (65). Consistent with its effects on glucose metabolism, mTOR inhibition broadly impaired cytotoxic NK cell functions, including IFN- $\gamma$, perforin, and granzyme $\mathrm{B}$ expression and degranulation and cytotoxicity in response to tumor cell targets $(56,63)$. Moreover, inhibition of either cMyc expression, Srebp activity, or the citrate-malate shuttle all critically impaired NK cell IFN- $\gamma$ production and cytotoxicity $(15,17)$. In human NK cells, elevated OxPhos is essential for NK cell cytotoxicity and IFN- $\gamma$ production in response to IL-2 and IL-15/IL-12 stimulation. Heightened glycolysis was also shown to be required for NK cell cytotoxicity following $24 \mathrm{~h}$ IL-15 stimulation and for a robust IFN- $\gamma$ response to IL-15/IL-12, particularly in CD56 $6^{\text {bright }} \mathrm{NK}$ cells $(18,60)$. Keating et al. demonstrated metabolic differences between CD56 ${ }^{\text {bright }}$ and CD56 ${ }^{\text {dim }}$ human pbNK cells $(60)$. In line with their greater cytotoxic functions following cytokine priming, CD56 ${ }^{\text {bright }}$ pbNK cells had enhanced mTOR-mediated expression of nutrient receptors and glucose uptake in response to cytokine stimulation as compared to CD56 ${ }^{\mathrm{dim}}$ pbNK cells. Thus, up-regulation of glucose-driven glycolysis and OxPhos 
characterizes and enables the activation of cytotoxic NK cell functions.

Accumulating evidence is demonstrating that the most highly cytotoxic NK cells are endowed with greater glucose-driven metabolic fitness. Extended pre-activation of NK cells for 3-5 days with IL-15 induces greater IFN- $\gamma$ production in response to receptor-mediated activation as compared to short-term (4-24 h) IL-15 pre-activation $(56,61)$. During extended IL- 15 stimulation, NK cells undergo profound metabolic reprogramming as compared to short-term stimulation, as they greatly increase both their rate and overall capacity for glycolysis and OxPhos (56, 61). Following such metabolic reprogramming, NK cell IFN- $\gamma$ production was no longer susceptible to the inhibition of $\mathrm{OxPhos}$ alone; rather, aggressive inhibition of both glycolysis and OxPhos by treating NK cells with oligomycin in glucose-free media was required to suppress IFN- $\gamma(61)$. Such metabolic reprogramming has demonstrated improved outcomes in the context of infection. Pre-treatment of mice with the IL-15 super-agonist complex ALT-803 for 3 days prior to MCMV infection increased basal and maximal glycolytic and oxidative metabolism and rescued impaired viral clearance in response to 2-DG treatment (18). Similar metabolic reprogramming also underpins the enhanced cytotoxic functions of licensed NK cells. The process of licensing during NK cell development requires that inhibitory KIRs expressed by the NK cell recognize self-MHC, the result of which lowers the threshold required for activation and enables greater effector potential in licensed NK cells compared to their unlicensed counterparts (66). Schafer et al. demonstrated that glycolytic metabolism is a critical regulator of NK cell licensing (21). In NK cells expanded with IL-21-expressing K562 feeder cells, highly functional licensed NK cells had greater glycolysis and glycolytic reserve compared to less functional unlicensed NK cells. Despite this increased conversion of glucose to lactate, expanded licensed NK cells sustained comparable levels of mitochondrial respiration as unlicensed NK cells, indicating a greater net level of glucose-derived energy production. While unlicensed NK cell cytotoxicity was highly sensitive to inhibition of OxPhos with oligomycin, the cytotoxicity of licensed NK cells was more resistant to metabolic inhibition. Similar to following extended IL-15 stimulation, the cytotoxicity of licensed NK cells was only inhibited upon aggressive abrogation of glucose metabolism by overnight incubation in glucose-free media, 2DG and oligomycin (21). Together, these findings demonstrate that a greater capacity for glucose-fueled energy production identifies NK cells with enhanced cytotoxic functions (Figure 2B). Moreover, greater metabolic fitness in these highly functional NK cells imparts greater flexibility in using either glycolysis or OxPhos to fuel their cytotoxic functions, rendering them more resistant to metabolic stressors.

A parallel emerges when considering the phenotype and metabolism of highly cytotoxic NK cells. It is known that upon extended cytokine stimulation including IL-15, in addition to increasing their capacity for glucose metabolism, NK cells also up-regulate CD56 expression and become predominantly CD56 bright (35). Indeed, evidence has separately demonstrated that 1) CD56 bright $\mathrm{pbNK}$ cells have a greater propensity for glucose metabolism compared to CD56 ${ }^{\mathrm{dim}} \mathrm{NK}$ cells (67), and 2) $\mathrm{CD}^{\text {bright }}{ }^{\text {pbNK }}$ cells have superior cytotoxicity and IFN- $\gamma$ production compared to CD56 dim $\mathrm{NK}$ cells following priming with IL-15 (38). Moreover, a recent report suggests that highly functional licensed expanded NK cells have greater CD56 expression than their less functional unlicensed counterparts. Following the same feeder cell expansion with IL-21-expressing K562 cells, expanded NK cell degranulation and IFN- $\gamma$ production increased with CD56 expression: the most cytotoxic and thus licensed NK cells were CD56 $6^{\text {superbright }}$ whereas the least cytotoxic were CD56 ${ }^{\mathrm{dim}}$ (40). Together these studies expose an inextricable tie between heightened cytotoxic potential, capacity for glucose metabolism, and degree of CD56 expression. Thus, in the context of cytotoxic NK cells, both CD56 expression and heightened glucose metabolism are indicative of subsets with the greatest functional capacity. However, highly functional regulatory $\mathrm{NK}$ cells are also $\mathrm{CD} 56^{\text {bright }}$, which raises the question: can distinct metabolic programs differentiate highly cytotoxic CD $56^{\text {bright }} \mathrm{NK}$ cells from highly regulatory CD $56^{\text {bright }}$ NK cells?

\section{Glucose Metabolism - The Weight That Tips the Balance Between Cytotoxic and Regulatory NK Cells?}

Research on NK cell metabolism has largely focused on the metabolic pathways that generate anti-viral and anti-tumor effector NK cells and it is clear that enhanced glucose metabolism is critical for such functions. On the other hand, while regulatory NK cells have critical homeostatic anti-inflammatory roles in the body, there is a dearth of knowledge about the role of metabolism in driving regulatory $\mathrm{NK}$ cell polarization and functions. In order to more fully understand the role of metabolism in the polarization of NK cell functions, it will be critical for future studies to investigate the metabolic profile of regulatory NK cells. For instance, is the metabolism of highly functional NK cells similar irrespective of whether the downstream functions are cytotoxic or regulatory? Or do regulatory NK cells predominantly utilize distinct, non-glucose-driven metabolic pathways which determine their regulatory functional fate?

The metabolism of a cell is largely dictated by its microenvironment, including factors such as nutrient and oxygen availability. Thus, in considering the above questions, it is worthwhile to examine microenvironments that favor regulatory NK cell polarization, such as the uterus, tumors, and the liver, and the metabolic profile these may shape:

Following implantation in the uterine endometrium, the early growth of the embryo occurs in hypoxic conditions in the uterus (68). Hypoxia in turn stimulates the secretion of VEGF and other angiogenic factors from uNK cells to support the demands for increased vascularization $(69,70)$. In addition, TGF $\beta$ plays an important role in inducing regulatory uNK cell functions (41, 6971). Many parallels are evident between regulatory uNK cells and tumor-associated (TA-)NK cells. As a result of rapid tumor cell proliferation, tumors have aberrant vascularization resulting in large pockets of hypoxia $(72,73)$. In addition, high levels of anti-inflammatory cytokines such as TGF $\beta$ are produced by other tumor-associated immune cells and are known to impair 


\section{B Cytotoxic}

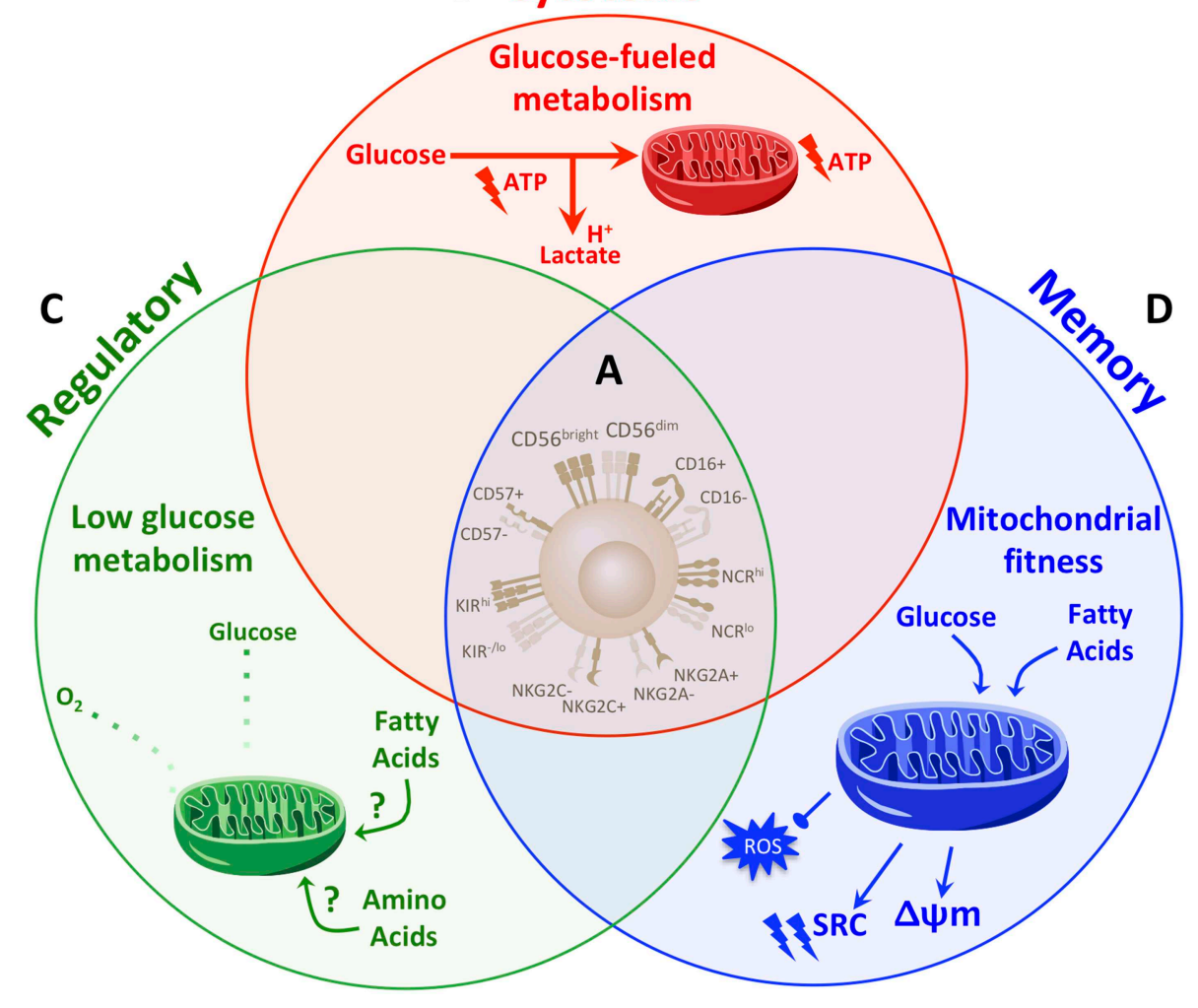

FIGURE 2 | Distinct metabolic fingerprints, but not phenotype, underpin NK cell functional fates. (A) Though widely used to define NK cell subsets, classic NK cell phenotypic markers are proving insufficient to comprehensively identify NK cell fates. The range of archetypal NK cell phenotypes are in fact expressed across NK cells with different functional fates. In the absence of distinguishable phenotypes to reliably determine NK cell fate and functional potential, determining what drives and identifies NK cell fate will be instrumental. (B-D) Studies so far have demonstrated that distinct metabolic profiles drive NK cell functions. (B) Cytotoxic NK cells are fueled primarily by glucose. Upon activation, cytotoxic NK cells increase rates of glucose-driven glycolysis and OxPhos which in turn drive cytotoxic functions. A greater capacity for glucose metabolism through glycolysis and OxPhos identifies NK cells with the greatest cytotoxic abilities. (C) NK cells are polarized to a regulatory fate under hypoxic and glycolysis-limiting conditions. Thus, regulatory functions are promoted under low levels of glycolysis and OxPhos and may rely on fuels other than glucose, such as fatty acids or amino acids. (D) Memory NK cells exhibit enhanced mitochondrial fitness. During the contraction phase of an immune response, NK cells undergo autophagy to clear dysfunctional mitochondria, which is required for the generation of a memory NK cell pool. Memory NK cells exhibit an increased spare respiratory capacity (SRC) and membrane potential $(\Delta \psi \mathrm{m})$ and reduced levels of reactive oxygen species (ROS). While memory $\mathrm{NK}$ cells maintain an enhanced capacity for glucose metabolism, they also up-regulate genes involved in lipid metabolism. Such a diversification in fuels in memory NK cells may provide metabolic adaptability to support longevity and the greater energy demands for enhanced function upon re-activation. Taken together, a paradigm in which distinct metabolic fingerprints comprehensively distinguish and drive the range of NK cell functional fates warrants further exploration.

NK cell anti-tumor functions (67). Similar to uterine NK cells, TA-NK cells in a number of cancers have been shown to have poor cytotoxicity, but secrete the angiogenic factors VEGF and PlGF and, through a mechanism involving TGF $\beta$, acquire a uNKlike $\mathrm{CD} 56^{\text {bright }} \mathrm{CD} 16^{-}$phenotype $(4,5,74)$. The liver is another site enriched in regulatory NK cells and anti-inflammatory cytokines including TGF $\beta$ and IL-10 (75, 76). Liver-resident NK cells have been shown to suppress the proliferation of $\mathrm{T}$ cells and $\mathrm{B}$ cells through their secretion of IL-10, and to inhibit the anti-viral activity of $\mathrm{T}$ cells through PD1/PDL1 engagement $(77,78)$. Moreover, the liver is predominantly hypoxic, with oxygen levels dipping as low as $1.3 \%$ in the healthy liver, which can be further exacerbated by infection and fibrosis (79-82). Hypoxia has been shown to be an important factor in limiting the anti-viral activity of NK cells in $\mathrm{HCV}+$ patients, but does not affect their regulatory activity against liver fibrosis (82).

Hypoxia and anti-inflammatory cytokines stand out as hallmarks across environments that foster regulatory NK cell functions. The critical role of hypoxia and TGF $\beta$ in directly polarizing NK cells to a regulatory state was highlighted by a study that demonstrated that in vitro culture of cytotoxic pbNK cells in TGF $\beta+$ IL-15 under hypoxic conditions was sufficient to convert pbNK cells to regulatory NK cells that secreted high levels of VEGF and had poor cytotoxicity (69). The induction of regulatory NK cells by hypoxia and TGF $\beta$ suggests that there are vastly different metabolic requirements for regulatory $\mathrm{NK}$ cell functions compared to the glucose-driven glycolytic and respiratory requirements for cytotoxic functions. In contrast to the ability of regulatory $\mathrm{NK}$ cells to thrive in hypoxic 
conditions and in line with the reliance of cytotoxic NK cells on glucose-driven OxPhos, hypoxia suppresses NK cell antitumor and anti-viral effector functions $(82,83)$. Studies have also demonstrated that TGF $\beta$ inhibits NK cell cytotoxic functions by suppressing glucose-driven glycolysis and OxPhos $(63,84)$. It follows then, that regulatory NK cell functions induced by TGF $\beta$ are not reliant on, and perhaps even inhibited by, elevated glucose metabolism. Further supporting this notion is a recent study which demonstrated that the tumor environment directly limits glycolysis in NK cells. The lung tumor microenvironment increased NK cell expression of fructose-1,6-bisphosphatase (FBP1), a rate-limiting enzyme in gluconeogenesis, which reduced glucose flux through glycolysis (85); thus, regulatory functions such as VEGF and PlGF production by TA-NK cells are unlikely to rely on elevated glucose metabolism. Another recent study demonstrated that in response to cytokine stimulation, regulatory liver-resident CD56 ${ }^{\text {bright }} \mathrm{NK}$ cells had lower expression of the glucose transporter Glut1, but higher expression of the amino acid transporter CD98 and the CD71 transferrin receptor compared to pbNK cells (86). These findings support a model in which regulatory NK cells are less reliant on glucose metabolism compared to cytotoxic NK cells, and may utilize other fuels, such as amino acids and/or fatty acids, to support their functions (Figure 2C).

Indeed, the evidence to date indicates that dependence on glucose-driven glycolysis and OxPhos may be a central node in tipping the balance between cytotoxic and regulatory NK cell fate. If this proves true, these distinct metabolic fingerprints would consistently distinguish cytotoxic from regulatory NK cells, addressing the drawbacks encountered in phenotypically defining these subsets. Future studies investigating the metabolic parameters that govern regulatory NK cell functions will be imperative to establishing this paradigm.

\section{Deep Breaths Bring Longevity-Mitochondrial Respiration at the Core of NK Cell Memory}

The generation of memory NK cells requires a shift from the energy-intensive effector phase of the immune response to a contraction phase, characterized by a curtailment in proliferation and effector functions, resulting in the generation of resting long-lived memory NK cells. The ability of memory NK cells to mount a more robust and rapid effector response upon re-stimulation compared to naïve activated NK cells suggests an enhanced ability to draw upon energy reserves upon re-activation. Given the fundamental shifts between energy expenditure and quiescence between effector, contraction, and recall phases of an immune response, it is perhaps not surprising that metabolic changes have been found to be both necessary and sufficient to drive the formation and enhanced recall responses of other memory immune cells $(29,30,87,88)$.

In NK cells, restoring mitochondrial function following an effector response has been shown to be critical in the generation of memory NK cells during murine CMV infection. O'Sullivan et al. demonstrated that during the peak of the effector phase in response to MCMV, virus-specific NK cells developed reduced mitochondrial fitness, marked by a decrease in mitochondrial membrane potential and increase in ROS production. In contrast, the contraction phase was marked by the clearance of dysfunctional mitochondria in NK cells through autophagy, resulting in the restoration of mitochondrial membrane potential and reduced ROS. The clearance of dysfunctional mitochondria through autophagy was required for the generation and survival of MCMV-memory NK cells, as the inhibition of autophagy impaired the formation of the memory NK cell pool, while treatment with an ROS scavenger restored memory formation. Further, enhancement of autophagic activity through the inhibition of mTOR or activation of the metabolic regulator AMPK enriched the memory-NK cell population (23).

Enhanced mitochondrial fitness has emerged as a defining characteristic of HCMV-adaptive NK cells in humans (Figure 2D). NK cells from HCMV-seropositive donors had greater levels of maximal respiration, but not glycolysis, compared to NK cells from seronegative donors. Further, sorted $\mathrm{CD}^{2} 6^{\mathrm{dim}} \mathrm{NKG} 2 \mathrm{C}^{+}$HCMV-adaptive NK cells had comparable basal levels of glycolysis and OxPhos, but an increased capacity for these pathways, compared to donor-matched $\mathrm{CD} 56^{\mathrm{dim}} \mathrm{NKG}^{-} \mathrm{C}^{-}$canonical $\mathrm{NK}$ cells. These findings indicate that adaptive NK cells have a greater ability to up-regulate glycolysis and OxPhos upon activation. The enhanced respiratory capacity of adaptive compared to canonical NK cells was supported by greater mitochondrial membrane potential and expression of genes involved in the electron-transport chain. The increased mitochondrial fitness of adaptive NK cells was found to be regulated by the chromatin-modifying protein ARID5B, and necessary for enhanced NK cell survival and effector function (22).

A question that remains to be addressed is which metabolic fuel(s) is/are primarily used by adaptive NK cells. The greater glycolytic capacity in HCMV-adaptive NK cells points to greater glucose metabolism. However, gene expression analysis of HCMV-adaptive NK cells also revealed an increase in genes involved in lipid catabolism (22). Interestingly, autophagy is a key regulator of lipid catabolism (89); thus, it is plausible that a diversification and flexibility in fuel sources contributes to the resilient longevity and recall effector response in HCMV-adaptive NK cells (Figure 2D).

Although the above studies have demonstrated a metabolic basis for the generation and function of memory NK cells, these have been limited to assessing adaptive NK cells in the context of CMV infection. While phenotypic variations span different memory NK cell subsets, the memory-traits of extended survival and enhanced recall effector responses, for which the metabolic adaptations are necessary in the context of CMV, are traits that remain consistent across memory NK cells. Thus it is likely that across memory NK cell subsets, increased mitochondrial fitness and fuel flexibility are broadly required to support longevity and that an enhanced respiratory capacity is necessary to derive the energy required for enhanced function upon re-activation. An important area of future study will be to verify that similar metabolic reprogramming 
broadly drives the formation and function of other memoryNK cell subsets, including cytokine-induced memory-like NK cells, BCG-memory NK cells, and pregnancy-trained uterine NK cells.

\section{CONCLUDING REMARKS}

Research on NK cell biology is continuing to evolve and uncover a wider scope of NK cell functional fates. However, as knowledge on the complexity and plasticity of NK cells has grown, so too have incongruities in the classic phenotypic definitions of NK cell subsets. Classic NK cell phenotypes have undoubtedly served as an accessible measure for profiling NK cells and provide indications on NK cell activation state. Nevertheless, in many instances phenotype in fact confounds functional fates, as NK cells that express the same phenotype can have divergent functions, and NK cells with similar functional potential can express a range of phenotypic possibilities. Indeed, identifiable phenotypes that are sufficient to profile NK cell functional fates are lacking (Figure 2A). The shortcomings of phenotype in informing function expose a need to further search for what identifies NK cell fate and develop strategies to efficiently profile NK cells by these factors. Turning to a central hub that governs NK cell fate holds promise to address these drawbacks.

Metabolism has emerged as an intriguing factor to distinguish NK cell functional fates. The field of NK cell metabolism is still in early stages, but studies so far point to distinct metabolic profiles as drivers of NK cell functional potential which may thus serve as reliable fingerprints to identify functional fates (Figures 2B-D). A heightened capacity for glucose metabolism through glycolysis and OxPhos identifies NK cells with the greatest cytotoxic capacity. In contrast, regulatory NK cells thrive in hypoxic and glycolysis-limiting conditions, suggesting that regulatory functions can be effected with minimal levels of OxPhos and glycolysis. Longevity in its essence requires adaptability and endurance-memory NK cells are marked by enhanced mitochondrial fitness, achieved by the clearance of dysfunctional mitochondria, increased mitochondrial respiratory capacity and membrane potential, and reduced levels of damaging reactive oxygen species. Collectively, the evidence to date suggests a paradigm in which distinct metabolic fingerprints, but not phenotype, comprehensively distinguish and drive the range of NK cell functional fates (Figure 2).

Certainly, significant questions remain to fully delineate and validate this paradigm. For instance, what metabolic fuels and pathways are principally used by regulatory NK cells? Are low levels of glucose metabolism sufficient to support regulatory functions or do regulatory NK cells use an alternate fuel, such as fatty acids, as a more efficient means of energy generation in low oxygen conditions? Does enhanced mitochondrial fitness span all memory NK cell types? Are there metabolic pathways that further distinguish memory cytotoxic from memory regulatory NK cells?
Are other factors, such as transcription markers and epigenetic modifications, required in conjunction with metabolism to determine NK cell fate? Such questions present exciting avenues for future research and will provide a more comprehensive understanding of the mechanisms and role of metabolism in tuning the spectrum of NK cell functions.

While metabolism is a promising means by which to identify NK cell fates, another critical question is whether it is achievable to efficiently profile NK cells based on metabolism. In this regard, similar to assessing classic phenotypic markers, a number of metabolic measures are frequently assessed via cytometry or microscopy, allowing for multiplex analyses that comprehensively measure a number of metabolic features. These include functional mitochondrial measures, such as mitochondrial mass, structure, membrane potential, ROS production, and oxidative stress $(22,29)$. Further, the relative activity of major metabolic regulators such as MTOR and AMPK are routinely measured by the phosphorylation status of these and their downstream targets $(16,56,60,90)$. Although not a direct measure of metabolic activity, the expression of cell surface nutrient receptors such as Glut1, CD71, and CD98 have been shown to reflect certain metabolic states in NK cells $(16,60)$. Finally, measuring the activities of key metabolic enzymes through cytometry has shown to be a valid and reliable means of assessing the metabolic configurations of immune cells and can additionally be accomplished in situ (91). With these applicable and efficient methods at hand, it will be imperative that future work characterize and validate combinations of metabolic measures that comprehensively indicate and discern the metabolic fingerprints of NK cell fates.

Given the critical and distinct roles that NK cells play in a host of diseases, therapeutically modulating NK cell function is garnering increasing attention. With distinct metabolic fingerprints at the heart of NK cell functional fates, profiling and modulating metabolism hold promise as powerful therapeutic strategies to predict and control NK cell fate.

\section{AUTHOR CONTRIBUTIONS}

SP designed and wrote the manuscript. AA designed and edited the manuscript.

\section{FUNDING}

This review was supported by grants awarded to AA from the Canadian Institutes of Health Research (CIHR) and the Juravinski Hospital and Cancer Center Foundation. AA holds a Tier 1 Canada Research Chair. SP is a recipient of a CIHR Vanier Scholarship, an Ontario Women's Health Scholars Award funded by the Ontario Ministry of Health and Long-Term Care and an Ontario Graduate Scholarship funded by the government of Ontario. 


\section{REFERENCES}

1. Vivier E, Tomasello E, Baratin T, Walzer T, Ugolini S. Functions of natural killer cells. Nat Immunol. (2008) 9:503-10. doi: 10.1038/ni1582

2. Bodduluru LN, Kasala ER, Madhana RM, Sriram CS. Natural killer cells: The journey from puzzles in biology to treatment of cancer. Cancer Lett. (2015) 357:454-67. doi: 10.1016/j.canlet.2014.12.020

3. Crome SQ, Nguyen LT, Lopez-Verges S, Yang SY, Martin B, Yam JY, et al. A distinct innate lymphoid cell population regulates tumor-associated $\mathrm{T}$ cells. Nat Med. (2017) 23:368-75. doi: 10.1038/nm.4278

4. Bruno A, Focaccetti C, Pagani A, Imperatori AS, Spagnoletti M, Rotolo N, et al. The proangiogenic phenotype of natural killer cells in patients with nonsmall cell lung cancer. Neoplasia. (2013) 15:133-42. doi: 10.1593/neo.121758

5. Levi I, Amsalem H, Nissan A, Darash-Yahana M, Peretz T, Mandelboim $\mathrm{O}$, et al. Characterization of tumor infiltrating natural killer cell subset. Oncotarget. (2015) 6:13835-43. doi: 10.18632/oncotarget.3453

6. Gamliel M, Goldman-Wohl D, Isaacson B, Gur C, Stein N, Yamin R, et al. Trained memory of human uterine NK cells enhances their function in subsequent pregnancies. Immunity.(2018) 48:951-62.e5. doi: 10.1016/j.immuni.2018.03.030

7. Hanna J, Goldman-Wohl D, Hamani Y, Avraham I, Greenfield C, Natanson-Yaron S, et al. Decidual NK cells regulate key developmental processes at the human fetal-maternal interface. Nat Med. (2006) 12:106574. doi: 10.1038/nm1452

8. Ashkar AA, Di Santo JP, Croy BA. Interferon gamma contributes to initiation of uterine vascular modification, decidual integrity, and uterine natural killer cell maturation during normal murine pregnancy. J Exp Med. (2000) 192:25970. doi: 10.1084/jem.192.2.259

9. Gur C, Doron S, Kfir-Erenfeld S, Horwitz E, Abu-Tair L, Safadi R, et al. NKp46-mediated killing of human and mouse hepatic stellate cells attenuates liver fibrosis. Gut. (2012) 61:885-93. doi: 10.1136/gutjnl-2011-301400

10. Jinushi M, Takehara T, Tatsumi T, Kanto T, Miyagi T, Suzuki T, et al. Negative regulation of NK cell activities by inhibitory receptor CD94/NKG2A leads to altered NK cell-induced modulation of dendritic cell functions in chronic hepatitis C virus infection. J Immunol. (2004) 173:607281. doi: 10.4049/jimmunol.173.10.6072

11. Jinushi $M$, Takehara $T$, Tatsumi $T$, Yamaguchi $S$, Sakamori R, Hiramatsu $\mathrm{N}$, et al. Natural killer cell and hepatic cell interaction via NKG2A leads to dendritic cell-mediated induction of CD4 CD25 T cells with PD-1-dependent regulatory activities. Immunology. (2007) 120:73-82. doi: 10.1111/j.1365-2567.2006.02479.x

12. Fehniger TA, Shah MH, Turner MJ, VanDeusen JB, Whitman SP, Cooper MA, et al. Differential cytokine and chemokine gene expression by human NK cells following activation with IL-18 or IL-15 in combination with IL-12: implications for the innate immune response. J Immunol. (1999) 162:4511-20.

13. Cooper MA, Fehniger TA, Caligiuri MA. The biology of human natural killer-cell subsets. Trends Immunol. (2001) 22:633-40. doi: 10.1016/S1471-4906(01)02060-9

14. Freud AG, Mundy-Bosse BL, Yu J, Caligiuri MA. The broad spectrum of human natural killer cell diversity. Immunity. (2017) 47:820-33. doi: 10.1016/j.immuni.2017.10.008

15. Assmann N, O’Brien KL, Donnelly RP, Dyck L, Zaiatz-Bittencourt V, Loftus RM, et al. Srebp-controlled glucose metabolism is essential for NK cell functional responses. Nat Immunol. (2017) 18:1197-206. doi: 10.1038/ni.3838

16. Donnelly RP, Loftus RM, Keating SE, Liou KT, Biron CA, Gardiner $\mathrm{CM}$, et al. mTORC1-dependent metabolic reprogramming is a prerequisite for $\mathrm{NK}$ cell effector function. J Immunol. (2014) 193:4477-84. doi: 10.4049/jimmunol.1401558

17. Loftus RM, Assmann N, Kedia-Mehta N, O’Brien KL, Garcia A, Gillespie $\mathrm{C}$, et al. Amino acid-dependent cMyc expression is essential for NK cell metabolic and functional responses in mice. Nat Commun. (2018) 9:2341. doi: 10.1038/s41467-018-04719-2

18. Mah AY, Rashidi A, Keppel MP, Saucier N, Moore EK, Alinger JB, et al. Glycolytic requirement for NK cell cytotoxicity and cytomegalovirus control. JCI Insight. (2017) 2:95128. doi: 10.1172/jci.insight.95128

19. Yang M, Chen S, Du J, He J, Wang Y, Li Z, et al. NK cell development requires Tsc1-dependent negative regulation of IL-15-triggered mTORC1 activation. Nat Commun. (2016) 7:12730. doi: 10.1038/ncomms12730
20. Yang M, Li D, Chang Z, Yang Z, Tian Z, Dong Z. PDK1 orchestrates early NK cell development through induction of E4BP4 expression and maintenance of IL-15 responsiveness. J Exp Med. (2015) 212:25365. doi: 10.1084 /jem. 20141703

21. Schafer JR, Salzillo TC, Chakravarti N, Kararoudi MN, Trikha P, Foltz JA, et al. Education-dependent activation of glycolysis promotes the cytolytic potency of licensed human natural killer cells. J Allergy Clin Immunol. (2019) 143:346-58.e6. doi: 10.1016/j.jaci.2018.06.047

22. Cichocki F, Wu C-Y, Zhang B, Felices M, Tesi B, Tuininga K, et al. ARID5B regulates metabolic programming in human adaptive NK cells. $J$ Exp Med. (2018) 215:2379-95. doi: 10.1084/jem.20172168

23. O'Sullivan TE, Johnson LR, Kang HH, Sun JC. BNIP3- and BNIPL-mediated mitophagy promotes the generation of natural killer cell memory. Immunity. (2015) 43:331-42. doi: 10.1016/j.immuni.2015.07.012

24. Michalek RD, Gerriets VA, Jacobs SR, Macintyre AN, N.J. M, Mason EF, et al. Cutting edge: distinct glycolytic and lipid oxidative metabolic programs are essential for effector and regulatory CD4+ T cell subsets. J Immunol. (2011) 186:3299-303. doi: 10.4049/jimmunol.1003613

25. Jha Abhishek K, Huang Stanley C-C, Sergushichev A, Lampropoulou V, Ivanova $\mathrm{Y}$, Loginicheva E, et al. Network integration of parallel metabolic and transcriptional data reveals metabolic modules that regulate macrophage polarization. Immunity. (2015) 42:419-30. doi: 10.1016/j.immuni.2015.02.005

26. Rodriguez-Prados JC, Traves PG, Cuenca J, Rico D, Aragones J, MartinSanz P, et al. Substrate fate in activated macrophages: a comparison between innate, classic, and alternative activation. J Immunol. (2010) 185:60514. doi: 10.4049/jimmunol.0901698

27. Chang CH, Curtis JD, Maggi LBJ, Faubert B, Villarino AV, O'Sullivan D, et al. Posttranscriptional control of $\mathrm{T}$ cell effector function by aerobic glycolysis. Cell. (2013) 153:1239-51. doi: 10.1016/j.cell.2013.05.016

28. Vats D, Mukundan L, Odegaard JI, Zhang L, Smith KL, Morel CR, et al. Oxidative metabolism and PGC-1beta attenuate macrophage-mediated inflammation. Cell Metab. (2006) 4:13-24. doi: 10.1016/j.cmet.2006.05.011

29. Buck MD, O'Sullivan D, Klein Geltink RI, Curtis JD, Chang CH, Sanin $\mathrm{DE}$, et al. Mitochondrial dynamics controls $\mathrm{T}$ cell fate through metabolic programming. Cell. (2016) 166:63-76. doi: 10.1016/j.cell.2016.05.035

30. van der Windt GJ, Everts B, Chang CH, Curtis JD, Freitas TC, Amiel E, et al. Mitochondrial respiratory capacity is a critical regulator of $\mathrm{CD} 8+\mathrm{T}$ cell memory development. Immunity. (2012) 31:68-78. doi: 10.1016/j.immuni.2011.12.007

31. Gerriets VA, Kishton RJ, Johnson MO, Cohen S, Siska PJ, Nichols AG, et al. Foxp3 and Toll-like receptor signaling balance Treg cell anabolic metabolism for suppression. Nat Immunol. (2016) 17:1459-66. doi: 10.1038/ni.3577

32. Bjorkstrom NK, Riese P, Heuts F, Andersson S, Fauriat C, Ivarsson MA, et al. Expression patterns of NKG2A, KIR, and CD57 define a process of CD56dim NK-cell differentiation uncoupled from NK-cell education. Blood. (2010) 116:3853-64. doi: 10.1182/blood-2010-04-281675

33. Yu J, Mao HC, Wei M, Hughes T, Zhang J, Park IK, et al. CD94 surface density identifies a functional intermediary between the CD56bright and CD56dim human NK-cell subsets. Blood. (2010) 115:274-81. doi: 10.1182/blood-2009-04-215491

34. Béziat V, Duffy D, Quoc SN, Le Garff-Tavernier M, Decocq J, Combadière $\mathrm{B}$, et al. CD56brightCD16+ NK cells: a functional intermediate stage of NK cell differentiation. J Immunol. (2011) 186:6753-61. doi: 10.4049/jimmunol.1100330

35. Takahashi E, Kuranaga N, Satoh K, Habu Y, Shinomiya N, Asano $\mathrm{T}$, et al. Induction of CD16+ CD56bright NK cells with antitumour cytotoxicity not only from CD16- CD56bright NK Cells but also from CD16- CD56dim NK cells. Scand J Immunol. (2007) 65:12638. doi: 10.1111/j.1365-3083.2006.01883.x

36. Streltsova MA, Erokhina SA, Kanevskiy LM, Lee DA, Telford WG, Sapozhnikov AM, et al. Analysis of NK cell clones obtained using interleukin2 and gene-modified K562 cells revealed the ability of "senescent" NK cells to lose CD57 expression and start expressing NKG2A. PLoS ONE. (2018) 13:e0208469. doi: 10.1371/journal.pone.0208469

37. Jacobs B, Tognarelli S, Poller K, Bader P, Mackensen A, Ullrich E. NK cell subgroups, phenotype, and functions after autologous stem cell transplantation. Front Immunol. (2015) 6:583. doi: 10.3389/fimmu.2015.00583 
38. Wagner JA, Rosario M, Romee R, Berrien-Elliott MM, Schneider SE, Leong JW, et al. CD56bright NK cells exhibit potent antitumor responses following IL-15 priming. J Clin Invest. (2017) 127:4042-58. doi: 10.1172/JCI90387

39. Lunemann S, Langeneckert AE, Martrus G, Hess LU, Salzberger W, Ziegler $\mathrm{AE}$, et al. Human liver-derived CXCR6 $(+) \mathrm{NK}$ cells are predominantly educated through NKG2A and show reduced cytokine production. J Leukoc Biol. (2019) 2015:1331-40. doi: 10.1002/JLB.1MA1118-428R

40. Poznanski SM, Nham T, Chew MV, Lee AJ, Hammill JA, Fan IY, et al. Expanded CD56superbrightCD16+ NK cells from ovarian cancer patients are cytotoxic against autologous tumor in a patientderived xenograft murine model. Cancer Immunol Res. (2018) 6:1174-85. doi: 10.1158/2326-6066.CIR-18-0144

41. Siewiera J, Gouilly J, Hocine HR, Cartron G, Levy C, Al-Daccak R, et al. Natural cytotoxicity receptor splice variants orchestrate the distinct functions of human natural killer cell subtypes. Nat Commun. (2015) 6:10183. doi: $10.1038 /$ ncomms 10183

42. Gaynor LM, Colucci F. Uterine natural killer cells: functional distinctions and influence on pregnancy in humans and mice. Front Immunol. (2017) 8:467. doi: 10.3389/fimmu.2017.00467

43. Verma S, King A, Loke YW. Expression of killer cell inhibitory receptors on human uterine natural killer cells. Eur J Immunol. (1997) 27:97983. doi: 10.1002/eji.1830270426

44. King A, Allan DS, Bowen M, Powis SJ, Joseph S, Verma S, et al. HLA-E is expressed on trophoblast and interacts with CD94/NKG2 receptors on decidual NK cells. Eur J Immunol. (2000) 30:1623-31. doi: 10.1002/1521-4141(200006)30:6\&lt;1623::AIDIMMU1623\&gt;3.0.CO;2-M

45. Sun JC, Beilke JN, Lanier LL. Adaptive immune features of natural killer cells. Nature. (2009) 457:557-61. doi: 10.1038/nature07665

46. O'Leary JG, Goodarzi M, Drayton DL, von Andrian UH. T cell- and B cell-independent adaptive immunity mediated by natural killer cells. Nat Immunol. (2006) 7:507-16. doi: 10.1038/ni1332

47. Cooper MA, Elliott JM, Keyel PA, Yang L, Carrero JA, Yokoyama WM. Cytokine-induced memory-like natural killer cells. Proc Natl Acad Sci USA. (2009) 106:1915-9. doi: 10.1073/pnas.0813192106

48. Foley B, Cooley S, Verneris MR, Pitt M, Curtsinger J, Luo X, et al. Cytomegalovirus reactivation after allogeneic transplantation promotes a lasting increase in educated NKG2C $<\sup >+</$ sup $>$ natural killer cells with potent function. Blood. (2012) 119:266574. doi: 10.1182/blood-2011-10-386995

49. Hammer Q, Ruckert T, Borst EM, Dunst J, Haubner A, Durek P, et al. Peptide-specific recognition of human cytomegalovirus strains controls adaptive natural killer cells. Nat Immunol. (2018) 19:45363. doi: 10.1038/s41590-018-0082-6

50. Guma M, Angulo A, Vilches C, Gomez-Lozano N, Malats N, Lopez-Botet M. Imprint of human cytomegalovirus infection on the NK cell receptor repertoire. Blood. (2004) 104:3664-71. doi: 10.1182/blood-2004-05-2058

51. Della Chiesa M, Falco M, Bertaina A, Muccio L, Alicata C, Frassoni F, et al. Human cytomegalovirus infection promotes rapid maturation of NK cells expressing activating killer Ig-like receptor in patients transplanted with NKG2C-/- umbilical cord blood. J Immunol. (2014) 192:14719. doi: 10.4049/jimmunol.1302053

52. Liu LL, Landskron J, Ask EH, Enqvist M, Sohlberg E, Traherne JA, et al. Critical role of $\mathrm{CD} 2$ co-stimulation in adaptive natural killer cell responses revealed in NKG2C-deficient humans. Cell Rep. (2016) 15:108899. doi: 10.1016/j.celrep.2016.04.005

53. Romee R, Schneider SE, Leong JW, Chase JM, Keppel CR, Sullivan $\mathrm{RP}$, et al. Cytokine activation induces human memory-like NK cells. Blood. (2012) 120:4751-60. doi: 10.1182/blood-2012-04-4 19283

54. Leong JW, Chase JM, Romee R, Schneider SE, Sullivan RP, Cooper MA, et al. Preactivation with IL-12, IL-15, and IL-18 induces CD25 and a functional high-affinity IL-2 receptor on human cytokine-induced memorylike natural killer cells. Biol Blood Marrow Transplant. (2014) 20:46373. doi: 10.1016/j.bbmt.2014.01.006

55. Suliman S, Geldenhuys H, Johnson JL, Hughes JE, Smit E, Murphy $M$, et al. Bacillus Calmette-Guerin (BCG) revaccination of adults with latent mycobacterium tuberculosis infection induces long-lived BCG-reactive $\mathrm{NK}$ cell responses. J Immunol.

(2016) 197:1100-10. doi: 10.4049/jimmunol.1501996

56. Marcais A, Cherfils-Vicini J, Viant C, Degouve S, Viel S, Fenis A, et al. The metabolic checkpoint kinase mTOR is essential for interleukin-15 signaling during NK cell development and activation. Nat Immunol. (2014) 15:74957. doi: 10.1038/ni.2936

57. Chiossone L, Chaix J, Fuseri N, Roth C, Vivier E, Walzer T. Maturation of mouse NK cells is a 4-stage developmental program. Blood. (2009) 113:548896. doi: 10.1182/blood-2008-10-187179

58. Wullschleger $\mathrm{S}$, Loewith $\mathrm{R}$, Hall $\mathrm{MN}$. TOR signaling in growth and metabolism. Cell. (2006) 124:471-84. doi: 10.1016/j.cell.2006.01.016

59. Male V, Nisoli I, Kostrzewski T, Allan DS, Carlyle JR, Lord GM, et al. The transcription factor E4bp4/Nfil3 controls commitment to the NK lineage and directly regulates Eomes and Id2 expression. J Exp Med. (2014) 211:63542. doi: 10.1084/jem.20132398

60. Keating SE, Zaiatz-Bittencourt V, Loftus RM, Keane C, Brennan K, Finlay DK, et al. Metabolic reprogramming supports IFN- $\gamma$ production by CD56bright NK cells. J Immunol. (2016) 196:2552-60. doi: 10.4049/jimmunol.1501783

61. Keppel MP, Saucier N, Mah AY, Vogel TP, Cooper MA. Activation-specific metabolic requirements for NK cell IFN-g production. J Immunol. (2015) 194:1954-62. doi: 10.4049/jimmunol.1402099

62. Mao Y, van Hoef V, Zhang X, Wennerberg E, Lorent J, Witt K, et al. IL-15 activates mTOR and primes stress-activated gene-expression leading to prolonged anti-tumor capacity of NK cells. Blood. (2016) 128:147589. doi: 10.1182/blood-2016-02-698027

63. Viel S, Marçais A, Guimaraes FS, Loftus R, Rabilloud J, Grau M, et al. TGF$\beta$ inhibits the activation and functions of NK cells by repressing the mTOR pathway. Sci Signal. (2016) 9:ra19. doi: 10.1126/scisignal.aad1884

64. Wang R, Dillon CP, Shi LZ, Milasta S, Carter R, Finkelstein $\mathrm{D}$, et al. The transcription factor Myc controls metabolic reprogramming upon $\mathrm{T}$ lymphocyte activation. Immunity. (2011) 35:871-82. doi: 10.1016/j.immuni.2011.09.021

65. Michelet X, Dyck L, Hogan A, Loftus RM, Duquette D, Wei K, et al. Metabolic reprogramming of natural killer cells in obesity limits antitumor responses. Nat Immunol. (2018) 19:1330-40. doi: 10.1038/s41590-018-0251-7

66. Kim S, Poursine-Laurent J, Truscott SM, Lybarger L, Song YJ, Yang L, et al. Licensing of natural killer cells by host major histocompatibility complex class I molecules. Nature. (2005) 436:709-13. doi: 10.1038/nature03847

67. Krneta T, Gillgrass A, Poznanski S, Chew M, Lee AJ, Kolb M, et al. M2polarized and tumor-associated macrophages alter NK cell phenotype and function in a contact-dependent manner. J Leukoc Biol. (2017) 101:28595. doi: 10.1189/jlb.3A1215-552R

68. Rodesch F, Simon P, Donner C, Jauniaux E. Oxygen measurements in endometrial and trophoblastic tissues during early pregnancy. Obstet Gynecol. (1992) 80:283-5.

69. Cerdeira AS, Rajakumar A, Royle CM, Lo A, Husain Z, Thadhani RI, et al. Conversion of peripheral blood NK cells to a decidual NK-like phenotype by a cocktail of defined factors. J Immunol. (2013) 190:393948. doi: 10.4049/jimmunol.1202582

70. Cavalli RC, Cerdeira AS, Pernicone E, Korkes HA, Burke SD, Rajakumar A, et al. Induced human decidual NKlike cells improve utero-placental perfusion in mice. PLoS ONE. (2016) 11:e0164353. doi: 10.1371/journal.pone.01 64353

71. Keskin DB, Allan DS, Rybalov B, Andzelm MM, Stern JN, Kopcow HD, et al. TGFbeta promotes conversion of CD16+ peripheral blood NK cells into CD16- NK cells with similarities to decidual NK cells. Proc Natl Acad Sci USA. (2007) 104:3378-83. doi: 10.1073/pnas.0611098104

72. Helmlinger G, Yuan F, Dellian M, Jain RK. Interstitial pH and $\mathrm{pO} 2$ gradients in solid tumors in vivo: high-resolution measurements reveal a lack of correlation. Nat Med. (1997) 3:177-82. doi: 10.1038/nm0297-177

73. Michiels C, Tellier C, Feron O. Cycling hypoxia: a key feature of the tumor microenvironment. Biochim et Biophys Acta. (2016) 1866:7686. doi: 10.1016/j.bbcan.2016.06.004

74. Nham T, Poznanski SM, Fan IY, Shenouda MM, Chew MV, Lee AJ, et al. Ex vivo-expanded NK cells from blood and ascites of ovarian cancer patients are cytotoxic against autologous primary ovarian cancer cells. Cancer Immunol Immunother. (2018) 67:575-87. doi: 10.1007/s00262-017-2112-x 
75. Tu Z, Bozorgzadeh A, Pierce RH, Kurtis J, Crispe IN, Orloff MS. TLRdependent cross talk between human Kupffer cells and NK cells. J Exp Med. (2008) 205:233-44. doi: 10.1084/jem.20072195

76. Schon HT, Weiskirchen R. Immunomodulatory effects of transforming growth factor-beta in the liver. Hepatob Surg Nutrit. (2014) 3:386406. doi: 10.3978/j.issn.2304-3881.2014.11.06

77. Yoshida O, Akbar SM, Chen S, Miyake T, Abe M, Murakami H, et al. Regulatory natural killer cells in murine liver and their immunosuppressive capacity. Liver Int. (2010) 30:906-12. doi: 10.1111/j.1478-3231.2010.02253.x

78. Zhou J, Peng H, Li K, Qu K, Wang B, Wu Y, et al. Liver-resident NK cells control antiviral activity of hepatic T cells via the PD-1-PD-L1 axis. Immunity. (2019) 50:403-17.e4. doi: 10.1016/j.immuni.2018.12.024

79. Carreau A, El Hafny-Rahbi B, Matejuk A, Grillon C, Kieda C. Why is the partial oxygen pressure of human tissues a crucial parameter? Small molecules and hypoxia. J Cell Mol Med. (2011) 15:1239-53. doi: 10.1111/j.1582-4934.2011.01258.x

80. Kessler M, Hoper J, Krumme BA. Monitoring of tissue perfusion and cellular function. Anesthesiology. (1976) 45:18497. doi: 10.1097/00000542-197608000-00007

81. Corpechot C, Barbu V, Wendum D, Kinnman N, Rey C, Poupon R, et al. Hypoxia-induced VEGF and collagen I expressions are associated with angiogenesis and fibrogenesis in experimental cirrhosis. Hepatology. (2002) 35:1010-21. doi: 10.1053/jhep.2002.32524

82. Wolter F, Glassner A, Kramer B, Kokordelis P, Finnemann C, Kaczmarek DJ, et al. Hypoxia impairs anti-viral activity of natural killer (NK) cells but has little effect on anti-fibrotic NK cell functions in hepatitis C virus infection. J Hepatol. (2015) 63:1334-44. doi: 10.1016/j.jhep.2015.08.008

83. Balsamo M, Manzini C, Pietra G, Raggi F, Blengio F, Mingari MC, et al. Hypoxia downregulates the expression of activating receptors involved in NK-cell-mediated target cell killing without affecting ADCC. Eur J Immunol. (2013) 43:2756-64. doi: 10.1002/eji.201343448

84. Zaiatz-Bittencourt V, Finlay DK, Gardiner CM. Canonical TGF-beta signaling pathway represses human NK cell metabolism. J Immunol. (2018) 200:393441. doi: 10.4049/jimmunol.1701461

85. Cong J, Wang X, Zheng X, Wang D, Fu B, Sun R, et al. Dysfunction of Natural Killer cells by FBP1-induced inhibition of glycolysis during lungcancer progression. Cell Metab. (2018) 28:243-55.e5. doi: 10.1016/j.cmet.2018.0 6.021

86. Salzberger W, Martrus G, Bachmann K, Goebels H, Hess L, Koch $\mathrm{M}$, et al. Tissue-resident NK cells differ in their expression profile of the nutrient transporters Glut1, CD98 and CD71. PLoS ONE. (2018) 13:e0201170. doi: 10.1371/journal.pone.0201170

87. Gubser PM, Bantug GR, Razik L, Fischer M, Dimeloe S, Hoenger G, et al. Rapid effector function of memory CD8 $+\mathrm{T}$ cells requires an immediateearly glycolytic switch. Nat Immunol. (2013) 14:1064-72. doi: 10.1038/n i. 2687

88. O'Sullivan D, van der Windt GJ, Huang SC, Curtis JD, Chang CH, Buck $\mathrm{MD}$, et al. Memory CD8(+) $\mathrm{T}$ cells use cell-intrinsic lipolysis to support the metabolic programming necessary for development. Immunity. (2014) 41:75-88. doi: 10.1016/j.immuni.2014.06.005

89. Singh R, Kaushik S, Wang Y, Xiang Y, Novak I, Komatsu M, et al. Autophagy regulates lipid metabolism. Nature. (2009) 458:1131-5. doi: 10.1038/nature07976

90. Blagih J, Coulombe F, Vincent EE, Dupuy F, Galicia-Vazquez G, Yurchenko E, et al. The energy sensor AMPK regulates $\mathrm{T}$ cell metabolic adaptation and effector responses in vivo. Immunity. (2015) 42:41-54. doi: 10.1016/j.immuni.2014.12.030

91. Miller A, Nagy C, Knapp B, Laengle J, Ponweiser E, Groeger $\mathrm{M}$, et al. Exploring metabolic configurations of single cells within complex tissue microenvironments. Cell Metab. (2017) 26:788-800.e6. doi: 10.1016/j.cmet.2017.08.014

Conflict of Interest Statement: The authors declare that the research was conducted in the absence of any commercial or financial relationships that could be construed as a potential conflict of interest.

Copyright (C) 2019 Poznanski and Ashkar. This is an open-access article distributed under the terms of the Creative Commons Attribution License (CC BY). The use, distribution or reproduction in other forums is permitted, provided the original author(s) and the copyright owner(s) are credited and that the original publication in this journal is cited, in accordance with accepted academic practice. No use, distribution or reproduction is permitted which does not comply with these terms. 